SECTION 5

Conclusion 



\title{
Addiction Publishing and the Meaning of [Scientific] Life
}

\author{
Thomas F. Babor, Kerstin Stenius and Jean O’Reilly
}

\begin{abstract}
Introduction
The global scientific discipline of addiction studies that has developed during the past half century would be impossible without the infrastructure of the publishing enterprise. At the core of this infrastructure lie the peer-reviewed scientific article and the expanding network of journals that publish such articles. Throughout this book, we have focused on publishing scientific articles in peer-reviewed journals because this is a key part of the meaning of scientific life. Publishing allows the scientist to communicate findings, ideas, and opinions within a forum representing the scientific community. In this final chapter, we will explore this theme in relation to addiction science, which for many highly trained researchers throughout the world has become a career commitment that is not only personally rewarding but also beneficial to society.

In brief, our argument is as follows: Science is meaningless unless it is communicated. Publication communicates scientific findings, and it is also the hallmark of a productive scientific career. Scientific integrity is another core feature of a successful career, and it must be nurtured by individuals, groups, and institutions, including scientific journals. To the extent that science constitutes a universal language, there is a special need to foster addiction careers in low- and middle-income countries.
\end{abstract}

\section{How to cite this book chapter:}

Babor, T F, Stenius, K and O'Reilly, J. 2017. Addiction Publishing and the Meaning of [Scientific] Life. In: Babor, T F, Stenius, K, Pates, R, Miovský, M, O'Reilly, J and Candon, P. (eds.) Publishing Addiction Science: A Guide for the Perplexed, Pp. 355-364. London: Ubiquity Press. DOI: https://doi.org/10.5334/bbd.q. License: CC-BY 4.0. 


\section{The Meaning of Science}

A seminal article by Ilkka Niiniluoto (2002), professor of philosophy at Helsinki University, traces the history of science through the various milestones in the search for knowledge from the time of the ancient Greeks to the present time.

The first milestone, which is the legacy of Aristotle, lies above all in the organized description of how we come to know the world and its generally accepted laws ("why" knowledge). A second phase in the history of science came with Galileo's search for regularities in how the world changes ("how" knowledge).

Compared with these steps, the third one is more complicated. A much later advance in the development of science began at the end of the 19th century when Charles Pierce introduced the notion of fallibility, which claimed that human beings constantly make mistakes in their search for knowledge and that all claims about the real world should be questioned. "This is true also of research, even if the scientific method of the research community, at least in the long run, is the most reliable way to produce and motivate conceptions of the world" (Niiniluoto, 2002, p. 32, authors' translation).

Niiniluoto talks about science as a self-correcting process. The modern scientific community has its own quality-assessment system (e.g., the peer review process), scientific claims are public, and all parties in the scientific community have the right to discuss, criticize, or refute those claims. According to Niiniluoto, contemporary science is characterized by objectivity (gaining as true a picture of the object studied as possible), a critical attitude (research should be public and open for critical discussion in the research community), autonomy (the scientific community operates independently of religious, political, economic, personal, and social influences), and progressivity (science creatively seeks new solutions and builds on old ones).

Arguing further that science is a social institution, Niiniluoto refers to Merton's (1973) four imperatives for the ethos of science: (a) universalism (the truth of claims shall be judged on impersonal grounds irrespective of the race, nationality, class, or personal characteristics of the person who presents them), (b) communism (scientific findings result from social cooperation and should be common property), (c) disinterestedness (scientists present and analyze scientific knowledge without considering the career or prestige of the researcher), and (d) organized skepticism (scientists assess scientific results on the bases of empirical and theoretical criteria).

According to Niiniluoto, Merton's principles have been criticized as deficient, insufficient, and inconsistent with the everyday life of research in the contemporary world. "Big science," increasing competition for personal repute, and the inequitable concentration of resources have eroded the ethos of science, as has the use of science in war and commercial production, which has produced a form of applied science that is businesslike and breaches the "communism" principle of common ownership of intellectual property. Niiniluoto argues, 
though, that this activity is not really scientia and should be viewed as something other than academic research.

In addiction research, the increasing competition for research positions and financial resources can foster the temptation to neglect ethical rules as well as the ethos of science. Career considerations can orient one's research to what is popular or fundable rather than toward what is interesting or important. The growth in private research funding may lead to secrecy instead of the open exchange of new ideas and research results, and may lead to new priorities that favor business interests rather than the public good.

If we accept Niiniluoto's assertions, we can understand why good publication practices, of the type described in this book, are crucial for science and the search for meaning in scientific life. Good publication practices represent the principles that should guide the quest for truth and, at the same time, demonstrate how to become a respected member of the scientific community. If science is to be used properly in the search for meaning as well as the basis for the betterment of humankind, there needs to be free access to the enormous reservoir of scientific knowledge in the world. That knowledge not only needs to be readily available, but it must also be recorded in a way that is understandable, useable, and certifiably scrutinized for error and bias. This is the role of journals and the responsibility of their authors. As noted by LaFollette (1992), a journal serves as the arbitrator of the authenticity and legitimacy of knowledge. It provides a historical record of a particular area of knowledge and confers implicit certification on authors for the originality of their work.

\section{Careers in Addiction Science}

Publishing with scientific integrity is for many the sine qua non of a productive scientific career in addiction science. The remarkable growth of addiction science worldwide (Babor, 1993, 2002; see also Chapter 2) coincides with the development of a variety of career options for those interested in basic, clinical, or social research. Research societies, subspecialties within professional organizations, and research centers have proliferated in many parts of the world, as has the availability of addiction specialty journals (see Chapter 3 ). There is growing evidence that a career in addiction science has become a viable and rewarding way to spend one's professional life (Edwards, 1991, 2002). As noted in Chapter 3, journals and the process of scientific publication serve the interests of career advancement and provide a vehicle for scholarly achievement. Indeed, the easiest way to understand a scientist's career is to review the publications proudly listed in his or her curriculum vitae. When one looks at the seminal thinkers and scientists in the field, published works constitute the main record of their professional lives. Boxes 17.1-17.2 provide examples of how productive and influential addiction researchers reflect on their research and scientific communications. 
Born in Antwerp, Belgium, in 1931, Charles S. Lieber received his medical degree in 1955. Soon thereafter, he moved to the United States and obtained senior research appointments at Harvard Medical School, Cornell Medical College, and Mount Sinai Medical School. His research focused on alcohol abuse and its biological components, including the mechanisms underlying the development of alcoholic cirrhosis of the liver (Edwards, 2002). In the following, he describes one of the discoveries that changed the course of biological research on alcohol:

"There seemed to be an adaptive system which helps us survive in modern society because it is relatively non-specific and detoxifies foreign compounds even when the body has never been exposed to them before. When we observed a similar morphological response after alcohol, I postulated that alcohol may therefore also be a substrate for this system. This hypothesis led to the discovery of the microsomal ethanol oxidizing system (MEOS) as a new pathway of ethanol metabolism" (Edwards, 2002, p. 19).

Box 17.1: Charles S. Lieber, M.d. (1931-2009).

In 1972, Martha Sanchez-Craig took a position as director of a halfway house for homeless alcoholics at the Addiction Research Foundation in Toronto, Canada. Five years later, she became a senior scientist at the Clinical Institute of the Addiction Research Foundation. Here, her research centered on brief interventions for people with alcohol- and other drug-related problems (Edwards, 2002). Despite her extensive publication career, she cautions about the "publish or perish" mentality:

"... one of the senior people, who was conducting experiments with small numbers of non-human subjects, said 'I don't have much regard for any scientist who doesn't publish at least six papers a year in peer-reviewed journals". I was very worried about that. I met colleagues who would get depressed or seriously worried if they couldn't publish a paper every month. I began to think that there are a lot of people here who like to do science that looks good, and only a few who like to do good science" (Edwards, 2002, p. 124).

Box 17.2: Martha Sanchez-Craig, Ph.d. 


\section{Individual Responsibility}

Research can be a solitary endeavor, involving late nights spent in your study or laboratory, preparations to defend a thesis or to question someone else's dissertation, and standing alone on a podium to present a scientific article. In many cases, it is impossible, at least without considerable effort, for an outsider to know whether a researcher has conducted his research ethically. All researchers are thus responsible for guarding the integrity of the public trust in research.

But research is also a highly social enterprise, which introduces its own ethical concerns. Much scientific research is now conducted via teams of investigators and support staff that share responsibility for the completion of a project and the publication of a scientific report. In this context, individual responsibility sometimes becomes diluted and ambiguous in relation to ethical matters. The research world is also very hierarchical. Younger researchers are like apprentices being trained by their masters, economically dependent on them for positions and promotions. These differential power relations can further dilute ethical responsibility.

Despite these threats to research integrity, addiction scientists must adhere to the ideal of the polis of the ancient Greeks, whereby every free man (we will have to ignore the gender discrimination of the time) was an equal, with similar responsibilities to decide matters of importance and civil rights to support those responsibilities. Similarly, every researcher must accept his or her personal responsibility for creating a more transparent and ethical addiction research community, which includes young investigators and senior researchers alike, as well as editors of journals and peer reviewers. Everyone, for example, has a responsibility to use citations in a fair and informative way (Chapter 10), to ensure the proper assignment of authorship credits (Chapter 11), and to adhere to ethical rules (Chapters 14, 15 and 16). When all researchers view themselves as equals in the republic of science, they will create the best foundation for creative discussions, which in turn will lead to progress in research.

\section{Creating Good Institutions}

In many instances, exhortations to individual responsibility are not enough to guarantee scientific integrity. Good institutions must support creative research milieus with sound ethical principles. Informal structures, such as open communication within departments (not only about research but also about ethical problems), the reading and critiquing of each other's work, democratic decision making, and cooperation on multidisciplinary projects all emanate from participatory norms and strong leadership. In Boxes 17.3-17.4, two influential addiction researchers reflect on the social and institutional aspects of their research and scientific communications. 
Mustapha I. Soueif was born in 1924. He completed his graduate studies in psychology at University of Cairo, Egypt. In addition to teaching psychology at the University of Cairo, he also worked for the World Health Organization (Edwards (1991). Here, he describes the challenges of publishing in different languages and the conflicts between having a national commitment and an international vision:

"It is a long time now that I have been living with this double identity; on the one hand I feel a world-citizen, on the other I belong to Egypt. This complex 'consciousness' or oscillating began in the late fifties when I was carrying out my first piece of clinical research in Egypt (at Abbassia Psychiatric Hospital) while keeping an eye on getting it published abroad. This was the paper on 'Testing for organicity in Egyptian psychiatric patients'. It was accepted for publication in Acta Psychologica (in Amsterdam). That was the first step towards establishing my reference group, defined in this case as a group of international scientists who would judge the worth of my research on its objective merits. My international identity, however, was definitely promoted through my contact with the WHO in Geneva. In 1966 I was approached by the WHO people to prepare a paper for publication in the UN Bulletin on Narcotics reporting on our work on 'Hashish Consumption in Egypt' which has been under way since 1957. This I did, and the paper was published in 1967. In 1970 I was invited to participate in a 'Scientific group' meeting to be held at WHO headquarters. The recognition my work received there was deeply gratifying” (Edwards, 1991, p. 436).

Box 17.3: Mustapha Soueif, Ph.d.

Also helpful to scientific integrity are more formal structures, such as policies for the ethical conduct of research (Chapter 15) and procedures for the determination of authorship credits (Chapter 11). In recent years addiction journals have emerged from their relatively obscure and modest origins to take a leadership role in the prevention of scientific misconduct. The ethical principles for authors included in this book represent the consensus of editors who are members of the International Society of Addiction Journal Editors. Integrity in scientific publishing can be enhanced only by education, vigilance, clear policies, and institutional norms that put science first.

\section{Awareness of Global Inequality}

Addiction is a global concern, and the concepts of universalism and autonomy suggest that knowledge gained from research should be shared 
Kettil Edmund Bruun received his doctoral training in sociology from the University of Helsinki. He is perhaps best known for his influential book, Alcohol Control Policies in Public Health Perspective, published in 1975 under the auspices of the World Health Organization. Sometimes called the "purple book" (owing to its cover in the English-language version), the publication gained wide attention for its basic tenet: "changes in the overall consumption of alcoholic beverages have a bearing on the health of the people in any society. Alcohol control measures can be used to limit consumption: thus, control of alcohol availability becomes a public health issue" (Bruun et al., 1975, p. 90; see also Edwards, 1991, and Room, 1986). In the following, Bruun describes with characteristic modesty the process that gave rise to the book:

"The background was that I had to rethink my ideas of alcohol control in the light of the Finnish experience in 1968/69 when controls had been suddenly relaxed with dramatic increase in consumption and harmful effects. My own liberal views on alcohol policies had received a blow. Then I was confronted in the European Office with international issues. I thought that I had to reconsider my position and that probably the best way to do it was to try to have a group which could develop a perspective beyond the specific situation in Finland. The situation was fortunate because many of the relevant questions had by then been focused for research. The group which emerged from my invitation did a marvelous job" (Edwards, 1991, pp. 371-372).

Box 17.4: Kettil Edmund Bruun, Ph.d. (1924-1985).

throughout the world. Unfortunately, resources for both research and scientific communications are limited in many parts of the world, and research conducted in the more-resourced countries often follows parochial national interests. Moreover, the dominance of English as the de facto language of science comes at a price for the majority of the world, in which other languages predominate.

Addiction researchers in the English-speaking and the more-developed countries have a special obligation to conduct and present their research, whenever possible, in a way that benefits the rest of humankind. The peerreview process should be open to scientists from all languages and nationalities, as should the editorial boards of the journals serving as the gatekeepers for scientific truth. Language and culture should not limit publication in addiction science. Not only is this a question of fairness, but it also speaks to the cross-cultural generalizability of scientific findings and the need to discover universal truths. 


\section{Conclusion: The Meaning of Scientific Life}

In Chapter 1, we referred to the medieval philosopher Maimonides and his Guide for the Perplexed. This was perhaps not a very modest analogy. We do not want to suggest that this book-or any book for that matter-can remove all confusion and provide a researcher with the guidance needed to have a successful career in addiction science. Rather, we hope the information in this book will lead its readers to the agora of science, a community square or common ground on which open and democratic discussions can take place among equals about the difficult problems all researchers, novices and career professionals alike, encounter in their everyday work.

One of those difficult problems is the meaning of scientific life itself. It is a question perhaps secondary to the broader question of life's meaning in general, but it is nevertheless worth asking if we want to make our own lives meaningful as addiction scientists. Various spiritual, religious, and philosophical traditions from the East, West, North, and South have contributed to this profound line of questioning.

Despite their important insights, biologist Edward O. Wilson (2014) believes philosophy is ill-equipped to tackle the meaning of existence. Wilson concludes that, by default, the task of explaining meaning necessarily falls to science itself. Among the disciplines that he favors in determining meaning are evolutionary biology and neuroscience. To those we would add the behavioral, social, and population sciences, which may help us understand how addiction is the antithesis of harmony with the natural world and how modern civilization seems designed to make that harmony difficult for many to achieve. And we should not defer entirely to science when meaning can surely be derived from religion, literature and other areas of knowledge.

In the most spiritual and reflective period of his life, Leo Tolstoy (1886) wrote a novella called The Death of Ivan Ilyich, which tells the story of the last days of a high-court judge in 19th-century Russia. It is at its core a philosophical commentary on the meaning of life as revealed in the interactions one has with family, work colleagues, and people encountered in day-to-day living at all social levels. What are the lessons for us, the living? One lesson is that if our lives are intimately invested in addiction science, this would be a good time to take inventory of what we have accomplished and what remains to be done. Have we avoided meaningless writing projects that lead to publications that nobody reads or values? Have we worked amicably with colleagues, supported their ideas, and given credit where it is due? Have we considered the plight of the alcoholic and the drug addict; the families who lose children to drunk drivers; and the evidence-based policies that could prevent drunk driving, fetal alcohol spectrum disorder, and underage drinking?

Beyond literature, science, and philosophy, perhaps the answer lies elsewhere. At the end of the Monty Python film, aptly called The Meaning of Life, the Lady 
Presenter addresses the question this way: "Well, it's nothing very special. Try to be nice to people, avoid eating fat, read a good book every now and then, get some walking in, and try and live together in peace and harmony with people of all creeds and nations." Or, as comedian Groucho Marx observed, "If you're not having fun, you're doing something wrong."

Ultimately, the meaning of scientific life is a question you will have to answer yourself. Even if a single answer to the question may elude you, that elusiveness is no great tragedy. More important is the search itself and the insights you gain as you realize that addiction science is a wonderful way to add benefit to society and depth to your own understanding of human nature. And finally, it is a way to have fun.

Please visit the website of the International Society of Addiction Journal Editors (ISAJE) at www.isaje.net to access supplementary materials related to this chapter. Materials include additional reading, exercises, examples, PowerPoint presentations, videos, and e-learning lessons.

\section{References}

Babor, T. F. (2002). In their own words: Conversations about the evolution of a specialist field. In G. Edwards (Ed.). Addiction: Evolution of a specialist field (pp. 383-389). Oxford, England: Blackwell Science.

Babor, T. F. (1993). Megatrends and dead ends: Alcohol research in global perspective. Alcohol Health and Research World, 17, 177-186.

Bruun, K., Edwards, G., \& Lumio, M., Mäkelä, K., Pan, L., Popham, R. E., . . , Österberg, E. (1975). Alcohol control policies in public health perspective. Helsinki, Finland: Finnish Foundation for Alcohol Studies, Vol. 25.

Edwards, G. (Ed.). (1991). Addictions: Personal influences and scientific movements. New Brunswick, NJ: Transaction Publishers.

Edwards, G. (Ed.). (2002). Addiction: Evolution of a specialist field. Oxford, England: Blackwell Science.

LaFollette, M. C. (1992). Stealing into print: Fraud, plagiarism, and misconduct in scientific publishing. Berkeley, CA: University of California Press.

Merton, R. (1973). The sociology of science: Theoretical and empirical investigations. Chicago, IL: University of Chicago Press.

Niiniluoto, I. (2002). Tieteen Tunnuspiirteet [The characteristics of science]. In S. Karjalainen, V. Launis, R. Pelkonen, \& J. Pietarinen (Eds.), Tutkijan Eettiset Valinnat [The ethical choices of the researcher], (pp. 30-41). Tampere, Finland: Gaudeamus. 
Room, R. (1986). Kettil Bruun, 1924-1985: An appreciation. The Drinking and Drug Practices Surveyor, 21, 1, 42-49.

Tolstoy, L. (1886). The Death of Ivan Ilyich. Russia.

Wilson, E. O. (2014). The meaning of human existence. New York, NY: Liveright Publishing Corporation. 